\title{
VAGINAL WALL HYPERPLASIA WITH FOLD PROLAPSE IN AN EIGHT-MONTH-OLD CANE CORSO DOG
}

\author{
T. A. AJADI ${ }^{1}$, O .L. AJAYI ${ }^{2}$, A. A. ADENIYI ${ }^{3}$ \& R. A. AJADI ${ }^{3}$ \\ ${ }^{1}$ Department of Veterinary Public Health \& Reproduction, ${ }^{2}$ Department of \\ Veterinary Pathology, ${ }^{3}$ Department of Veterinary Medicine and Surgery; \\ Federal University of Agriculture, Abeokuta, Nigeria
}

\section{Summary}

Ajadi, T. A., O. L. Ajayi, A. A. Adeniyi \& R. A. Ajadi, 2016. Vaginal wall hyperplasia with fold prolapse in an eight-month-old Cane Corso dog. Bulg. J. Vet. Med., 19, No 3, 252-258.

\begin{abstract}
An eight-month-old, female Cane Corso bitch was presented for treatment following complaint of protrusion of oedematous tissue through the vulva lips one week after the commencement of the oestrous cycle. Clinical examination revealed a pear-shaped fibrous vaginal mass measuring about $5 \mathrm{~cm}$ in diameter. Ultrasonography identified a single follicular cyst in the left ovary and vaginal smear cytology revealed $100 \%$ keratinised cells. The treatment involved repositioning of the vaginal prolapse with lacing of the vulva lips, hormonal therapy and surgical amputation of the protruding tissue. The dog had completely recovered after the treatment with no recurrence of prolapse. It had a physiological oestrus during the next cycle, was mated naturally and conceived a normal viable litter.
\end{abstract}

Key words: bitch, vaginal hyperplasia, vaginal prolapse

Vaginal prolapse, a clinical condition that is commonly seen in bitches is the protrusion of oedematous vaginal tissue into the vaginal lumen and often through the vulva lips of intact bitches during the proestrus or oestrus phase of the ovarian cycle (Deniz nak \& Gulnar, 2008). This disorder is caused by accentuation of the normal increase in vaginal hyperaemia and oedema secondary to the oestrogen stimulus occurring during proestrus and oestrus (Schaefers-Okkens, 2001). The vaginal and vulvar mucosa normally become very oedematous during the follicular phase of the oestrous cycle. This results in the detection of vaginal hyperplasia during prooestrus or oestrus of young bitches and is regressed during dioestrus (SchaeferesOkkens, 2005).

An exaggeration of this oestrogenic response can result in excessive mucosal folding of the vaginal floor just cranial to the urethral papilla, such that redundant mucosa begins to protrude through the vulvar labia. The exposed tissue rapidly becomes oedematous and inflamed and is easily traumatised (Suresh Kumar et al., 2011). 
A vaginal fold prolapse may occur in the young bitch during the first or second follicular phase under oestrogen influence and may reoccur at each subsequent oestrus, if not properly treated (SchaefersOkkens, 2001). However, treatment depends on the extent of the fold prolapse, whether one is dealing with a breeding or non-breeding bitch and whether or not the prolapse is present during oestrus or at the end of pregnancy which is seen in exceptional cases (Schaefers-Okkens, 2001). Based upon the degree of vaginal fold prolapse, Schutte (1967) has described a three stage classification scheme in dogs. Bitches with type I prolapse have slightto-moderate eversion of vaginal mucosa originating from the vaginal floor cranial to the urethral opening; type II prolapse indicates protrusion of the vaginal mucosa through the vulvar labia, with the base also originating from the vaginal floor; bitches with type III prolapse have complete protrusion of the entire circumference of the vaginal mucosa, often accompanied by exteriorisation of the urethral orifice.

An ovarian cyst is a fluid-filled structure (Olson et al., 1989) of any size present outside physiological prooestrus and oestrus within the ovary (Johnston et al., 2001). It can occur solitaire or multiple in one or on both ovaries (Dow, 1960) and is endocrinely active or inactive (Olson et al. 1989). Hormonally active ovarian cysts are of high clinical relevance because they are a significant source of hyperoestrogenism in bitches (Johnston et al., 2001), which may result in prolonged oestrus (Arlt et al., 2011; Knauf et al., 2013). There are different types of ovarian cysts: follicular cysts, cysts of subsurface epithelial structures (SES), cystic rete ovarii, lutein cysts and cystic corpora lutea (Johnston et al., 2001; Schlafer \& Miller,
2007). Follicular cysts are known to be endocrinely active e.g. produce oestradiol$17 ß$ and progesterone (Olson et al., 1989), similarly to progesterone-producing lutein cysts and cystic corpora lutea (McEntee, 1990; Johnston et al., 2001).

The present report describes the evaluation and management of a bitch diagnosed with vaginal fold prolapse and follicular cyst with no recurrence and subsequent normal heat, conception and parturition.

An eight-month-old female intact Cane corso bitch weighing $32 \mathrm{~kg}$ was presented to the Veterinary Teaching Hospital of the Federal University of Agriculture, Abeokuta, Nigeria with vaginal bloody discharge and a protruded mass around the vulva which was observed by the owner a week following the onset of her first oestrous cycle. The bitch was presented $>$ day 28 of first proestrual bleeding and was reported to be attracted to males but not standing for mating. On physical examination the rectal temperature, pulse and respiratory rates of the patient were within reference ranges. Vaginal bleeding, vulva oedema and a pear-shaped fibrous vaginal mass measuring about $5 \mathrm{~cm}$ in diameter was seen protruding out of the vulva on inspection of the genital tract (Fig. 1). The surface of the mass was smooth with some degree of contamination with sand but there was no evidence of necrosis of the mass.

Large number of non-cornified cells consisting predominantly of parabasal cells, small and large intermediate cells and few superficial cells were observed in the vaginal cytology (Fig. 2) stained with Giemsa stain confirming that the bitch was still in mid-proestrus stage with a $60 \%$ vaginal cornification indicative of vaginal hyperplasia. A diagnosis of type II vaginal prolapse was made based on the vaginal 


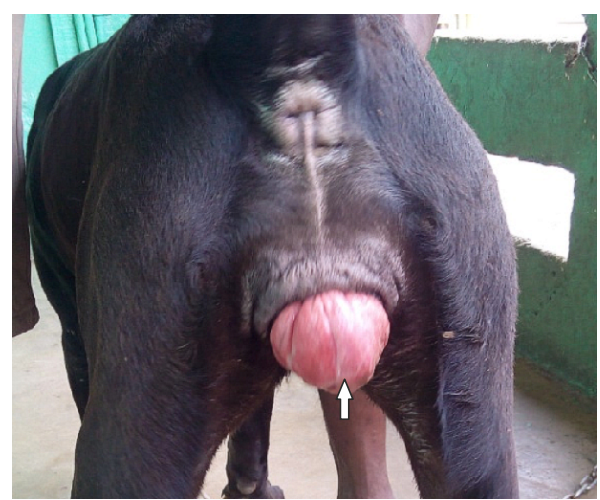

Fig. 1. Pear-shaped mass of vaginal fold prolapse from the vulva of the patient.

hyperplasia along with the glistening, pale pink protruded vaginal mucosa through the vulva labia without involvement of the entire circumference of the mucosa. Transcutaneous abdominal ultrasound was performed using a portable ultrasound machine (Kaixin KX 2000 ${ }^{\mathrm{R}}$, Xuzhou, China) fitted with a $3.5 \mathrm{MHz}$ curvilinear transducer. Ultrasound examination revealed moderately enlarged hypoechoic ovary with central anechoic ovarian cyst measuring about $4 \mathrm{~cm}$ in diameter (Fig. 3).

Following the diagnostic evaluation of the bitch, the mass was cleaned with normal saline and sterile gauze, carefully pushed back into its normal position but prolapsed back after a few hours. Thereafter, the mass was repositioned back and the vulva lips were partially sutured with purse string sutures so as to retain the mass inside and prevent desiccation and self-mutilation by the bitch.

Hormonal therapy was then planned to resolve the follicular cyst by initiating ovulation. Human chorionic gonadotropin (HCG) (Novarel ${ }^{\circledR}$ ) was administered intramuscularly daily for 4 days at a dose of 500 I.U. The placed sutures were removed five days after completion of the hormonal therapy. It was observed that the mass had reduced and no longer prolapsed out of the vulva. However, the prolapse reoccurred with a bigger mass of $8 \mathrm{~cm}$ in di-

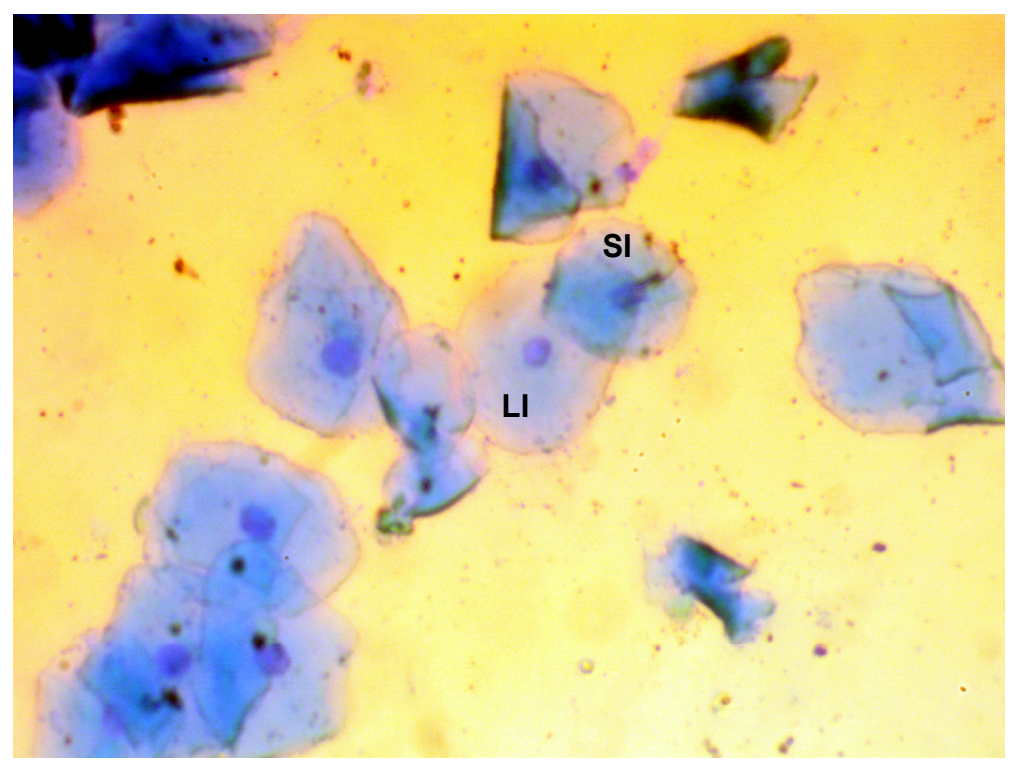

Fig. 2. Vaginal cytology smear showing predominantly small (SI) and large intermediate (LI) cells indicative of follicular phase of oestrous cycle. 


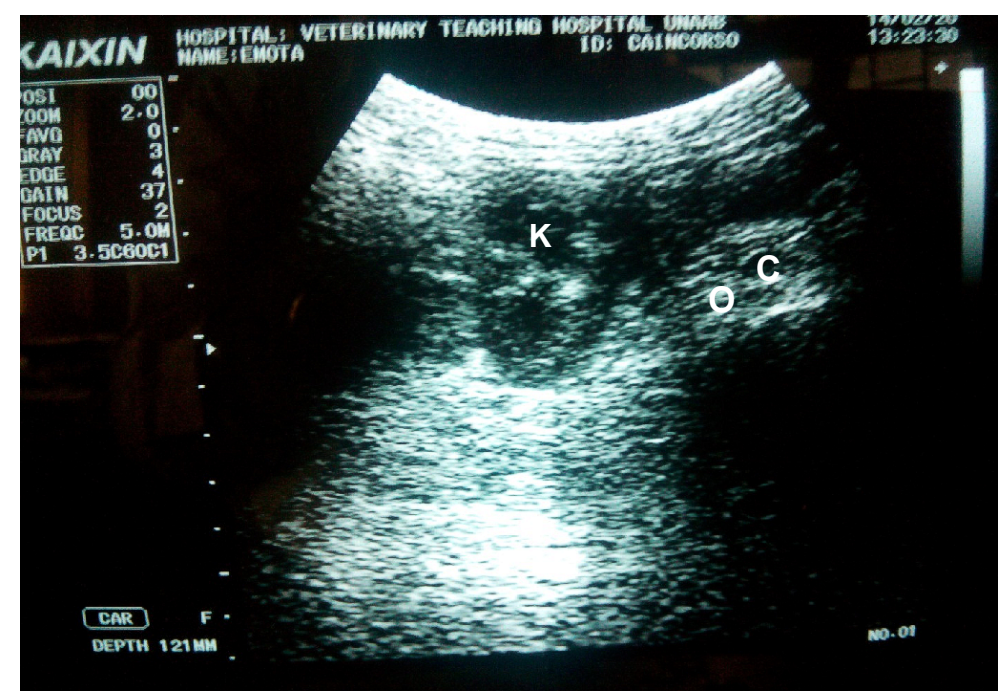

Fig. 3. Transcutaneous abdominal B-mode ultrasound of the 8-month-old Cane Corso with vaginal hyperplasia showing cyst $(\mathrm{C})$ in the ovary $(\mathrm{O})$ and a proximally located kidney $(\mathrm{K})$.

ameter protruding through the vulva in a pendulous manner in less than 24 hours after suture removal. Thus it was decided to carry out surgical resection of the mass.

The dog was first pre-medicated with intramuscular injection of $3 \mathrm{mg} / \mathrm{kg}$ of $5 \%$ tramadol hydrochloride (Amadol ${ }^{\circledR}$, Union Korea Pharma, Korea) followed $30 \mathrm{~min}$ later with intramuscular injections of 0.03 $\mathrm{mg} / \mathrm{kg}$ of $0.1 \%$ atropine sulphate (Amopin $^{\circledR}$, Yanzhou Pharmaceuticals, China) and $1 \mathrm{mg} / \mathrm{kg}$ of $2 \%$ xylazine hydrochloride (XYL-M2 ${ }^{\circledR}$, V.M.D, Germany). In addition, $3 \mathrm{~mL}$ of lignocaine was infiltrated into the lumbosacral epidural place to ensure proper analgesia of the perineal area and reduce the dosage of the anaesthetic induction agent. Thereafter, anaesthesia was induced and maintained with intravenous injections of $0.2 \mathrm{mg} / \mathrm{kg}$ of $0.5 \%$ diazepam (Calmpose ${ }^{\circledR}$ Ranbaxy, India) and $10 \mathrm{mg} / \mathrm{kg}$ of $5 \%$ ketamine hydrochloride (Ketamin hydrochloride USP ${ }^{\circledR}$, Rotex Medica, Germany). Following premedication, venous access was secured with a size 21 gauge scalp vein needle and the cardiovascular system supported with lactated Ringer's solution at a rate of $0.2 \mathrm{~mL} / \mathrm{kg} / \mathrm{min}$.

Following anaesthesia, the prolapsed vagina was rinsed with normal saline solution. Thereafter, a purse string suture was placed round the neck of the vagina to ensure that a large proportion of the prolapsed hyperplastic vagina was included in the resection. Ligatures were placed on visible blood vessels using size 0 chromic catgut. The pear-shaped prolapsed portion of vagina was then carefully resected with a scalpel. Care was taken not to occlude the vestibule. Mattress suture pattern with size 0 chromic catgut was used to appose the end of the resected vagina mucosa and also to control bleeding. The remnant of the vagina tissue was allowed to retract inward. The resected tissue was fixed in $10 \%$ buffered formaldehyde and sectioned for histopathology. Following recovery, the dog was treated with $100 \mathrm{mg}$ of tramadol orally twice daily for five days 
and penicillin-streptomycin injection (PenStrep $^{\circledR}$, Kepro, Holland) was administered intramuscularly for seven days. Histopathology of the mass revealed loosely arranged un-encapsulated proliferation of stellate to spindle shaped cells. There are few giant cells and moderate to numerous lymphocytes suggestive of vaginal hyperplasia with chronic inflammation (Fig. 4).

Vaginal prolapse is usually seen in younger bitches $(<2$ to 3 years of age) during their first three oestrous cycles. No breed preposition has been described, although it appears that the incidence of the condition is higher in large-breed bitches (Johnston et. al., 2001). The animal in this case is an 8-month-old bitch and in her first heat. This may be because first heat usually presents with an abnormal oestrous cycle and in this case there was an abnormal cycle due to the follicular cyst present in the left ovary which was secreting oestrogen and in turn provoked the vaginal prolapse. Ovarian follicular structures greater than $8 \mathrm{~mm}$ present during proestrus or oestrus prior to ovulation or follicles of any size present any time during late oestrus (post ovulation), dioestrus or anoestrus are defined as follicular cysts (Johnston et al., 2001). In this present case, the bitch had prolonged proestrus which is correlative to the findings of Johnston et al., (2001) who reported cycle irregularity exhibited as irregular interoestrus interval and prolonged proestrus or oestrus as the most common presenting clinical signs of cystic ovarian follicular diseases.

Vaginal prolapse is usually categorised into type I, II, and III depending on the extent of protrusion of the mass, type III or true vaginal prolapse has been earlier reported to occur near parturition as a result of decreasing progesterone and an elevation in oestrogen concentration (Veeraieah \& Srinivas, 2010). It sometimes occurs concurrent with the exteriorisation of other organs, such as the bladder, uterine body, or distal part of the colon (Gouletsou et al., 2009). This case was a type II vaginal prolapse because the prolapse did not involve the entire vaginal wall.

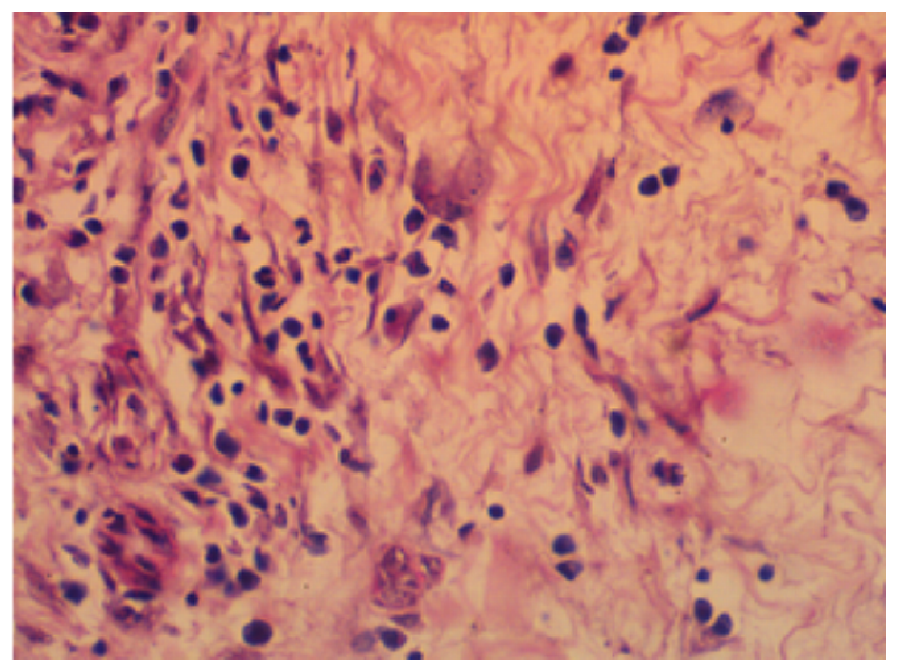

Fig. 4. Photomicrograph of the vagina of an 8-month-old Cane Corso with vaginal hyperplasia showing numerous spindle-shaped cells with moderate to numerous lymphocytes and few giant cells. 
Gonadotropin releasing hormone $(\mathrm{GnRH})$ has been used to treat vaginal hyperplasia in the bitch which results in release of $\mathrm{LH}$ and cause a subsequent rise in the serum concentration of progesterone (Wykes, 1986). The vaginal smear cytology results obtained in this case showed that the bitch was exhibiting persistent proestrus as a result of presence of the follicular cyst. Hormonal therapy used as a treatment modality in this case gave a temporary relief with reoccurrence of the prolapsed tissue one week post treatment, thus surgical excision of the prolapsed tissue was eventually used. Kim et al. (2008) also reported a similar case of vaginal fold prolapse developing as a result of multiple follicular cysts in the ovary of a bitch. According to their report, the vaginal tissue responded to $\mathrm{GnRH}$ treatment but three months later recurrence occurred and the authors adopted surgical resection. Although, surgical excision with ovariohysterectomy was earlier reported as preferred choice of treatment of vaginal prolapse (Mostachio et al., 2007). Only surgical resection was done in this case because the owner still desired to use the bitch for future breeding. This seems to be in agreement with Wykes (1986) who stated that surgical resection is the treatment of choice for vaginal fold prolapse in breeding animals, since the exposed hyperplastic tissue is aesthetically displeasing to many owners in addition to interfering with coitus.

In conclusion, vaginal prolapse is usually seen in younger bitches ( $<2$ to 3 years of age) during their first three oestrous cycles. Hormonal therapy, surgical resection and ovariohysterectomy are various modalities of treatment that could be adopted in the management. In the present case report, only surgical resection was done because the bitch was to be used for future breeding. The bitch had an interoestrus interval of five months, her succeeding cycle was uneventful without ovarian cysts and vaginal prolapse. She was thereafter mated, conceived and whelped five live puppies.

\section{REFERENCES}

Arlt, S. P., S. Spankowsky \& W. Heuwieser, 2011. Follicular cysts and prolonged oestrus in a female dog after administration of a deslorelin implant. New Zealand Veterinary Journal, 59, 87-91.

Deniz nak, Y. \& Y. Gulnaz, 2008. First report of vaginal prolapse in an ovariohysterectomised bitch - a case report. Bulletin of the Veterinary Institute in Pulawy, 52, 397-398.

Dow, C., 1960. Ovarian abnormalities in the bitch. Journal of Comparative Pathology, 70, 59-69.

Gouletsou, P. G., A. D. Galatos, K. Apostolidis \& A. I. Sideri, 2009. Vaginal fold prolapse during the last third of pregnancy, followed by normal parturition in a bitch. Animal Reproduction Science, 112, 371-376.

Johnston, S. D., M. V. Kustritz \& P. N. S. Olson, 2001. Disorders of canine ovary. In: Canine and Feline Theriogenology, eds. S. D. Johnston, M. V. Kustritz \& P. N. S. Olson, Philadelphia: Saunders, pp. 193-205.

Kim, B. S., H. S. Kim, K. C. Kim, C. H. Park, K. S. Oh \& C. H. Son, 2008. Vaginal prolapse by ovarian follicular cysts in a female Jin-do dog. Korean Journal of Veterinary Research, 48, 223-225.

Knauf, Y., K. Failing, S. Knauf, \& A. Wehrend, 2013. Treatment of bitches with ovarian cysts using human chorionic gonadotropin-releasing hormone analogon. A case series of 30 bitches. Tierärztliche Praxis, 41, 93-100.

McEntee, K., 1990. Cysts in and around the ovary. In: Reproductive Pathology of Do- 
Vaginal wall hyperplasia with fold prolapse in an eight-month-old Cane Corso dog

mestic Animals, eds. K. McEntee, Academic Press, San Diego, pp. 52-67.

Mostachio, G. Q., W. R. R. Vicente, D. J. Cardilli, E. A. Pires \& G. H. Toniollo, 2007. Anovulvar cleft and vaginal prolapse hyperplasia in a bitch. Journal of Small Animal Practice, 48, 713-715.

Olson, P. N., R. H. Wrigley, P. W. Husted, R. A. Bowen \& T. A. Nett, 1989. Persistent estrus in the bitch. In: Textbook of Veterinary Internal Medicine, eds. S. J. Ettinger \& E. C. Feldman, Philadelphia: Saunders, pp. 1792-1796.

Schaefers-Okkens, A. C., 2001. Vaginal oedema and vaginal fold prolapse in the bitch, including surgical management. In: Recent Advances in Small Animal Reproduction, eds. P. W. Concannon G. England \& J. Verstegen, International Veterinary Information Service (www.ivis. org), Ithaca, New York. Document No. A1210.0401

Schaeferes-Okkens, A. C., 2005. Estrous cycle and breeding management of the healthy bitch. In: Textbook of Veterinary Internal Medicine, eds. S. J. Ettinger \& E. C. Feldman, W. B. Saunders Co., London, p. 1641.

Schlafer, D. H. \& R. B. Miller, 2007. Female genital system. In: Jubb, Kennedy and Palmer's Pathology of Domestic Animals. $4^{\text {th }}$ edition, eds. M. G. Maxie, Philadelphia: Elsevier Saunders pp. 429-564.

Schutte, A. P. 1967. Vaginal prolapse in the bitch. Journal of South African Veterinary Association, 38, 197-203.
Suresh Kumar, R. V., P. Veena, P. Sankar, N. Dhana Lakshmi, Ch. Sreelatha \& Kokila, 2011. Vaginal hyperplasia in a dog - a case report. Tamilnadu Journal of Veterinary \& Animal Sciences, 7, 174-175.

Veeraiah, G. \& M. Srinivas, 2010. Spontaneous extrusion of the intestines and uterus as a sequeal to vaginal prolapse in a buffalo heifer: A case report. Buffalo Bulletin, 29, 60-64.

Wykes, P. M,. 1986. Diseases of the vagina and vulva in the bitch. In: Current Therapy in Theriogenology: Diagnosis, Treatment and Prevention of Reproductive Diseases in Small and Large Animals, ed. D. A. Morrow, W. B. Saunders Co., London, pp. 476-481.

Paper received 24.03.2015; accepted for publication 15.06.2015

\section{Correspondence:}

T. A. Ajadi

Department of Veterinary Public

Health and Reproduction

Federal University of Agriculture, Abeokuta

PMB 2240, Alabata Road, Abeokuta,

Ogun State, Nigeria

tel: 234-803-956-0868

e-mail: ayisat_ajadi@yahoo.com 